\section{Public Health} Genomics
Public Health Genomics 2016;19:325-335

DOI: $10.1159 / 000452094$
Received: January 28, 2016

Accepted: September 28, 2016

Published online: November 4, 2016

\title{
Participation in Genetic Research: Amazon's Mechanical Turk Workforce in the United States and India
}

\author{
Susan W. Groth Ann Dozier Margaret Demment Dongmei Li \\ I. Diana Fernandez Jack Chang Timothy Dye \\ University of Rochester, Rochester, NY, USA
}

\author{
Keywords \\ Attitudes - Beliefs - Bioethics - Concerns - Ethics of genetic \\ research · Genetic research · Human population · Social \\ representation
}

\begin{abstract}
Background: Genomic research has innumerable benefits. However, if people are unwilling to participate in genomic research, application of knowledge will be limited. This study examined the likelihood of respondents from a high- and a low- to middle-income country to participate in genetic research. Methods: Cross-sectional data were collected using Amazon's Mechanical Turk workforce to ascertain attitudes toward participation in genetic research. Registered country of residence was either the US $(n=505)$ or India $(n=505)$. Multiple logistic regression models were used to assess adjusted effects of demographic characteristics, health, social status, beliefs and concerns on 4 genetic research outcomes. Results: Participants from India who believed chance and powerful others influenced their health were more likely to participate in genetic research $(\mathrm{OR}=1.0,95 \% \mathrm{Cl} 1.0-1.1)$ and to agree with sharing of DNA data (OR $=1.1,95 \% \mathrm{Cl} 1.1-1.2)$. US participants were more likely to be concerned about protection of family history, which they indicated would affect
\end{abstract}

\section{KARGER}

(c) 2016 S. Karger AG, Basel

E-Mail karger@karger.com

www.karger.com/phg participation (OR $=3.6,95 \% \mathrm{Cl} 2.1-6.0)$. Commonalities for the likelihood of participation were beliefs that genetic research could help find new treatments (India OR $=2.3,95 \%$ Cl 1.0-5.4; US OR $=4.7,95 \% \mathrm{Cl} 2.0-11.2)$ and descendants would benefit (India OR $=2.6,95 \% \mathrm{Cl} 1.2-5.5$; US OR $=3.0$, $95 \% \mathrm{Cl} 1.3-7.1)$. Conclusions: Concurrence of beliefs on benefits and concerns about genetic research suggest they may be common across countries. Consideration of commonalities may be important to increase global participation in genetic research.

(c) 2016 S. Karger AG, Basel

\section{Introduction}

Genetic research has the potential to help prevent and improve disease burden throughout the world [1]. Genomic research has innumerable potential benefits, yet there are ethical challenges due to genetic data being identifiable, personal [2], immortal [3], and familial [4]. If individuals, families, and social groups are unwilling to participate in genetic research, the expansion of knowledge and medical modalities will be severely hampered because advances may only be applicable to those who participate in genetic research. Dimensions underlying 
genomic research (e.g., participation) are not equally accepted by all populations and understanding these elements could ensure equal benefit from precision medicine research [5]. The objective of this article is to describe the likelihood of respondents from a high- and a low- to middle-income country to participate in genetic research and to identify commonalities across these 2 countries.

In 2002, the World Health Organization (WHO) [1] sponsored a report that recommended that member countries develop ethical frameworks to guide genomic research and application within the unique context (e.g., religious, social, cultural) of their particular country. They also recommended that international-level guidelines be determined based on fundamental principles. The WHO deemed international debate as essential to identify underlying commonalities and concerns.

Since that time, global progress has been made in initiation of ethical approaches to genomic research with the creation of international partnerships focused on integration of genomic concepts into population understanding and the development of regulation guidelines for research [6]. Biobanks, both private and public, have proliferated and recommendations have been made for the management of genomic research at an international level [7]. Yet, a recent report from the WHO indicates that lowand middle- income countries are not benefiting from the application of genetic research as much as high-income countries [8]. Even so, low- to middle-income countries such as India, with its genetically heterogeneous population, have made a concerted effort to advance genomic applications (e.g., Indian genome variation consortium) [9]. However, there is a lack of acceptance of genetic research and application due to limited knowledge and mistrust, coupled with concerns about confidentiality, privacy, allocation of resources and public awareness [9].

Research focused on the likelihood of individuals to donate specimens for genetic research has examined various aspects of participation such as race, socioeconomic status, beliefs, and concerns, yet most have not provided a compilation of these elements together as central to participation in genetic research. We have a limited understanding of who is likely to participate in genetic research and at what levels they will participate (e.g., a particular study only vs. sharing data more widely). Ethical questions surrounding genomic research are far from being resolved. As genomic research continues to expand on the global level, there is undoubtedly a need to address pertinent concerns at the individual level to ensure subject participation, equality of benefit and global sharing of data. Assessment and comparison of different popula- tions is needed to expand what we know about who is likely to participate in such research globally. Demonstration of similarities across cultural groups on reasons individuals would choose to participate or not participate would provide a base from which to intervene and/or address the elements that contribute to nonparticipation and in this manner increase equal distribution of benefits. The goal of this study was to identify the similarities between survey respondents from the US (high-income country) and India (low- to middle-income country) in terms of likelihood of participation in genetic research and agreement to varying uses of their genetic material, based on individual characteristics, traits, beliefs, and concerns. Understanding who is willing to participate among diverse global groups has important implications for the generalizability of genetic research findings.

\section{Methods}

\section{Design}

Data from a large cross-sectional survey of participants who comprise Amazon's Mechanical Turk (mTurk) workforce [10, 11] were used to assess who is likely to participate in genomic research. The mTurk platform established by Amazon enables companies and researchers to engage global workers to complete "human intelligence tasks" (tasks that are easy for people but difficult for computers) for small per-transaction payments. In addition to providing a global digital workforce, mTurk enables the conduct of online research in which this workforce may participate $[11,12]$. The entire participant pool for this project was drawn from the mTurk workforce, estimated to exceed 500,000 individuals worldwide [12]. mTurk workers were invited to participate in a survey about helping better understand attitudes, beliefs, and knowledge about some topics related to medical care and research. Participants were offered compensation of USD 0.50 to complete the survey.

To ensure mTurk was an appropriate platform for our research we conducted a pilot study that was open to 7 regions: North America, South America, Europe, South Asia, East Asia, Africa, and Australia $(n=108)$. The goals of the pilot study were to identify problematic questions based on respondent feedback and determine the breadth of the sample globally. The pilot study ran from October 27, 2014 to November 6, 2014. The majority of respondents to the pilot survey found the questions understandable $(81 \%, n=88)$, the meaning of the questions straightforward $(97 \%$, $n=105)$, and the scales or responses adequate $(87 \%, n=94)$. Questions that respondents identified as problematic were edited. While there were respondents from all global regions, India and the US were the only 2 countries that provided a sufficient sample size and therefore were the focus of the main study. For the main study, potential participants were identified from the mTurk platform and organized by country of residence. Participation was limited to the US $(n=505)$ or India $(n=505)$ using the mTurk Local Qualification variable (country of residence for which a potential participant's account is registered) as a filter for eligibility for a 
Table 1. Variables, units of measure and source of questions posed to subjects

\begin{tabular}{ll}
\hline Age & continuous \\
Gender & male/female \\
Education & high school or less/undergraduate/graduate \\
Socioeconomic status & yes/no \\
$\quad$ - Car ownership & yes/no \\
$\quad$ Chouse ownership & Christian/Judaism/Muslim/Buddhism/Hindu/Atheist/don't know/other \\
Religion & 4-item set of healthy days core questions [32] \\
General health status & degree of agree/disagree, 5-point Likert scale [33] \\
Beliefs about genetic research & yes/no [34] \\
Concerns about genetic research & 6-point Likert scale [15] \\
Multidimensional Health Locus of Control & yes/no [16] \\
Ethical positioning & \\
\hline
\end{tabular}

particular country or region's survey. The sample size for the main study was determined by what was sufficient to explore both main effects and potential interactions. Based on an estimated mTurk workforce population size of 500,000 and a conservative response rate of $50 \%$ for each question, we needed at least 384 subjects to participate in our survey for $5 \%$ margin of error with $95 \%$ confidence level based on the method used for calculating the sample size needed for conducting surveys [13]. The main study started on November 14, 2014 and ended on March 4, 2015.

\section{Variables/Measures}

The survey deployed through mTurk included a variety of questions related to sociodemographics, ethical positions, health status, beliefs related to genetic research, and concerns about participating in genetic research (Table 1).

In this analysis, we focused on the following variables to help us understand the characteristics of participants from the US and India who were likely to participate in genetic research. Statements previously used by Green et al. [14] assessed willingness to participate in genetic research: (1) I would participate in research that used my DNA; (2) I would participate in research where my DNA was used for something other than the main study goal; (3) I would allow my DNA to be shared with a private company; and (4) I would allow my DNA to be used to create cell lines, which would allow for my DNA to be used in future studies [14]. Responses to each statement were based on a 5-point Likert scale from very likely to very unlikely. In our final analysis, those that were very likely or likely were compared to those that were neutral, unlikely, or very unlikely.

To assess the beliefs about the source of reinforcements for health-related behaviors, the Multidimensional Health Locus of Control Scales were used [15]. There are 18 questions on a 6-point Likert scale with 3 main scales: internal, a matter of chance, or under the control of powerful others with a range in responses of 6-36. The powerful others scales can be further divided into doctors and others scales that have a range of 3-18.

Ethical positioning, or personal moral philosophy, was assessed using Forsyth's Ethics Position Questionnaire [16]. There are 11 questions about their acceptance of items on a 5-point Likert scale with 2 scales: relativism and idealism. The relativism scale included items that capture how what is ethical could vary from one situation to another. The idealism scale, in contrast, measures
Table 2. Characteristics of US and India participants

\begin{tabular}{|c|c|c|}
\hline \multirow[t]{2}{*}{ Variable } & \multicolumn{2}{|c|}{ Total sample, $n(\%)$} \\
\hline & India $(n=505)$ & US $(n=505)$ \\
\hline \multicolumn{3}{|l|}{ Age } \\
\hline Mean $\pm S D$, years & $31.3 \pm 8.7$ & $35.4 \pm 12.1$ \\
\hline Range, years & $18-69$ & $18-74$ \\
\hline Missing, $n$ & 2 & 5 \\
\hline \multicolumn{3}{|l|}{ Gender } \\
\hline Male & $347(70)$ & $198(40)$ \\
\hline Female & $150(30)$ & $300(60)$ \\
\hline Missing & 8 & 7 \\
\hline \multicolumn{3}{|l|}{ Education } \\
\hline High school or less & $43(8)$ & $203(41)$ \\
\hline Undergraduate & $311(62)$ & $201(40)$ \\
\hline Graduate level & $143(29)$ & $93(19)$ \\
\hline Missing & 8 & 8 \\
\hline \multicolumn{3}{|l|}{ Owns a car } \\
\hline Yes & $192(38)$ & $401(81)$ \\
\hline No & $307(61)$ & $94(19)$ \\
\hline Missing & 6 & 10 \\
\hline \multicolumn{3}{|l|}{ Owns a home } \\
\hline Yes & $335(67)$ & $214(43)$ \\
\hline No & $154(31)$ & $278(56)$ \\
\hline Missing & 16 & 13 \\
\hline \multicolumn{3}{|l|}{ Christian } \\
\hline Yes & $92(18)$ & $276(57)$ \\
\hline No & $407(82)$ & $210(43)$ \\
\hline Missing & 6 & 19 \\
\hline \multicolumn{3}{|l|}{ Muslim } \\
\hline Yes & $57(11)$ & $6(1)$ \\
\hline No & $442(89)$ & $480(99)$ \\
\hline Missing & 6 & 19 \\
\hline
\end{tabular}

one's perspective on positive and negative consequences [16]. Individuals who have a higher concern for the welfare of others tend to have higher scores on the idealism score, while those that reject a universal ethic tend to have higher relativism scores [17]. The relativism and idealism subscales can be divided by the median and 


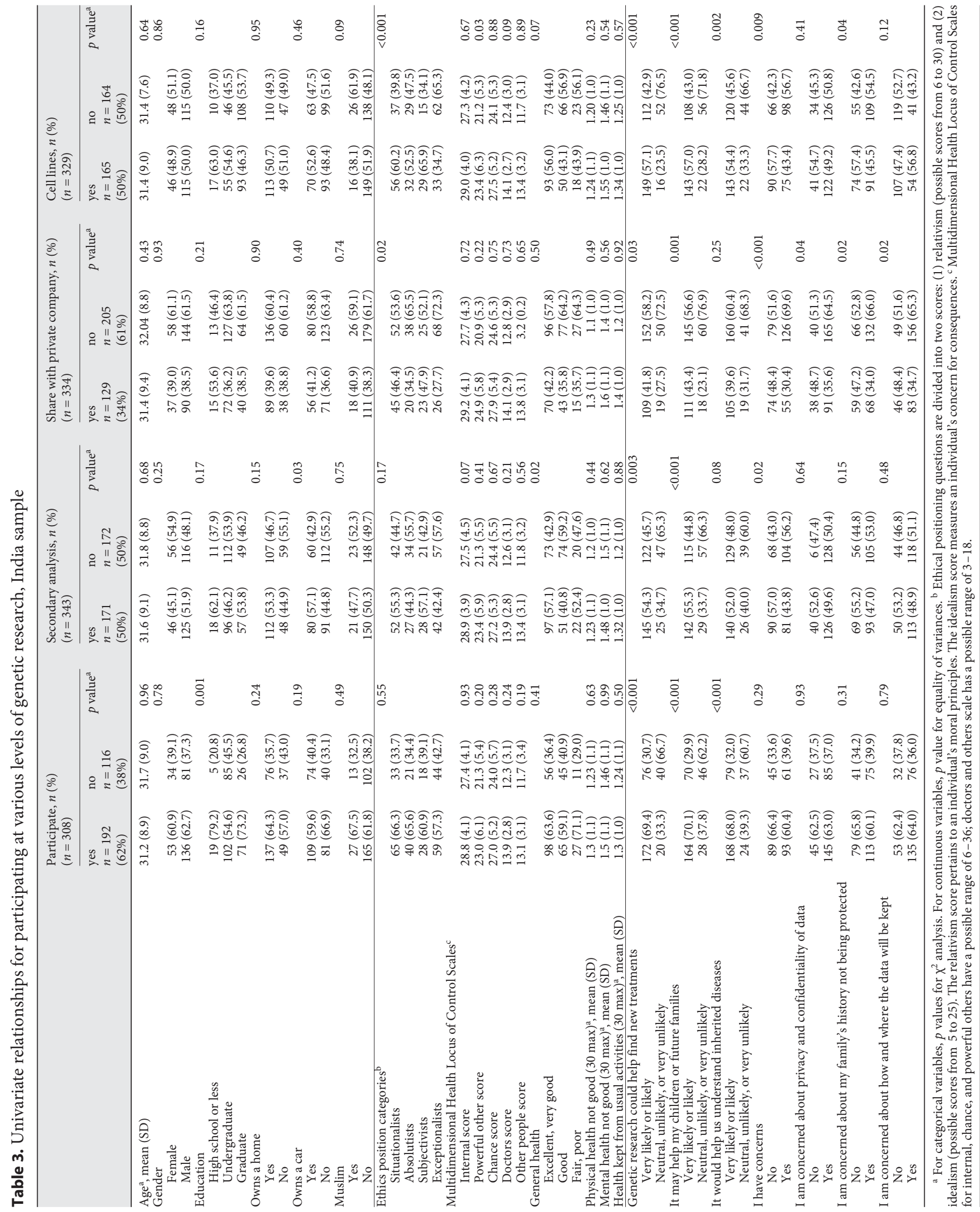


used to create 4 categories based on: (1) "situationalists": high idealism and high relativism - they are idealist contextualists who favor securing the best possible consequence for all concerned, even if doing so will violate traditional rules that define what is right and what is wrong; (2) "absolutists": high idealism and low relativism - they are principled idealists who believe people should act in ways that are consistent with moral rules, for doing so will in most cases yield the best outcomes for all concerned; (3) "subjectivists": low idealism and high relativism - they are pragmatic relativists who base their ethical choices on personal considerations, such as individualized values, moral emotions, or an idiosyncratic moral philosophy; and (4) "exceptionists": low idealism and low relativism - they are principled pragmatists who endorse moral rules as guides for action, but admit that following rules will not necessarily generate the best consequences for all concerned.

\section{Statistical Analysis}

Frequency distributions and summary statistics were used to describe the characteristics of the mTurk survey participants. $\chi^{2}$ tests were conducted to compare the differences in demographic characteristics, health, and psychosocial status between India participants and US participants. The unadjusted effects of demographic characteristics and health social status on genetic research outcomes (participate in genetic research, use DNA for secondary analysis, share DNA with a private company, and use DNA to create cell lines) were examined using univariate logistic regression models for India and US participants separately. Multiple logistic regression models were used to assess the adjusted effects of those demographic characteristics and health social status on genetic testing outcomes for either India or US participants. Subjects with missing observations were excluded in the multiple logistic regression models analysis. For each multiple logistic regression model, the significant covariates were selected using Hosmer and Lemeshow's purposeful model selection method. Odds ratios and their 95\% confidence intervals were used to estimate the effects of those demographic and social status variables on genetic testing outcomes. The Hosmer and Lemeshow goodness-of-fit tests were conducted to examine the goodness-of-fit of those multiple logistic regression models. All analyses were conducted using statistical analysis software SAS v9.4 (SAS Institute Inc., Cary, NC, USA). The significance levels for all tests were set at $5 \%$.

There was no evidence of particular questions consistently being avoided by participants, thus we considered the data missing at random. There were no significant differences between those who answered and those who did not in the India sample. In the US sample, a lower percentage of those who responded to the participation in genetic research question owned their own home (41 vs. $53 \%$ ) compared to those who did not answer and a higher percentage were Christian (46 vs. $33 \%$ ).

This research was reviewed and approved by the University of Rochester's Research Subjects Review Board.

\section{Results}

US participants ranged in age from 18 to 69 years, with a mean age of 35.4 (SD 12.1) and Indian participant ages ranged from 18 to 74 years, with a mean age of 31.3 (SD
8.7) (Table 2). Gender varied by country: $40 \%$ of US participants were male while $70 \%$ of India participants were male. US participants had a greater portion of high school graduation or less (41\%) while India participants had a greater proportion of undergraduate education (62\%). Individuals from both countries were similar in terms of how they perceived their health. From a socioeconomic perspective, Indian participants were less likely to own a car than US participants, while more US participants did not own a house. US participants were most likely to identify as Christian (69\%) while India participants were more likely to identify as Hindu (69\%). Univariate analyses for each of the genetic research questions are presented in Tables 3 and 4.

The Hosmer and Lemeshow goodness-of-fit tests demonstrated all multiple logistic regression models examined in this study had a good fit to the data (all had nonsignificant $p$ values). The India sample had a slightly higher proportion of participants who were willing to participate in genetic research compared to the US participants (62 vs. 57\%). In the India sample, those with a high school education or less had higher odds of participating in genetic research compared to more educated participants $(\mathrm{OR}=4.2,95 \% \mathrm{CI} 1.4-12.7)$ (Table 5). Those who believed chance played a role in their health had higher odds of participating ( $\mathrm{OR}=1.1,95 \%$ CI $1.0-1.1$ ), and agreed with sharing of DNA data for secondary data analysis (OR $=1.1,95 \% \mathrm{CI} 1.0-1.1)$ or a private company $(\mathrm{OR}=1.1,95 \%$ CI 1.0-1.1). Similarly, those who believed that powerful others played a role in their health had higher odds of agreeing to sharing data for secondary data analysis, with a private company and for use in cell lines (Table 5).

US participants who expressed that they had concerns about participating had lower odds of participating in genetic research $(\mathrm{OR}=0.5,95 \% \mathrm{CI} 0.3-1.0)$. These concerns also affected willingness to have their genetic data used for secondary analysis, by private companies or for cell lines (Table 6). US participants had higher odds of being concerned about the protection of family history which they indicated would affect participation $(\mathrm{OR}=3.6,95 \%$ CI 2.1-6.0), sharing data with private companies $(\mathrm{OR}=$ $2.2,95 \%$ CI 1.2-4.1) or for cell lines (OR $=2.7,95 \%$ CI 1.5-4.9). They were also more concerned about how and where data would be kept when shared with private companies (OR $=2.3,95 \%$ CI 1.2-4.6) and for cell lines $(\mathrm{OR}=1.8,95 \%$ CI $0.9-3.8)$.

Commonalities between India and US participants for odds of participation were beliefs that genetic research could help find new treatments $(\mathrm{OR}=2.3,95 \%$ 


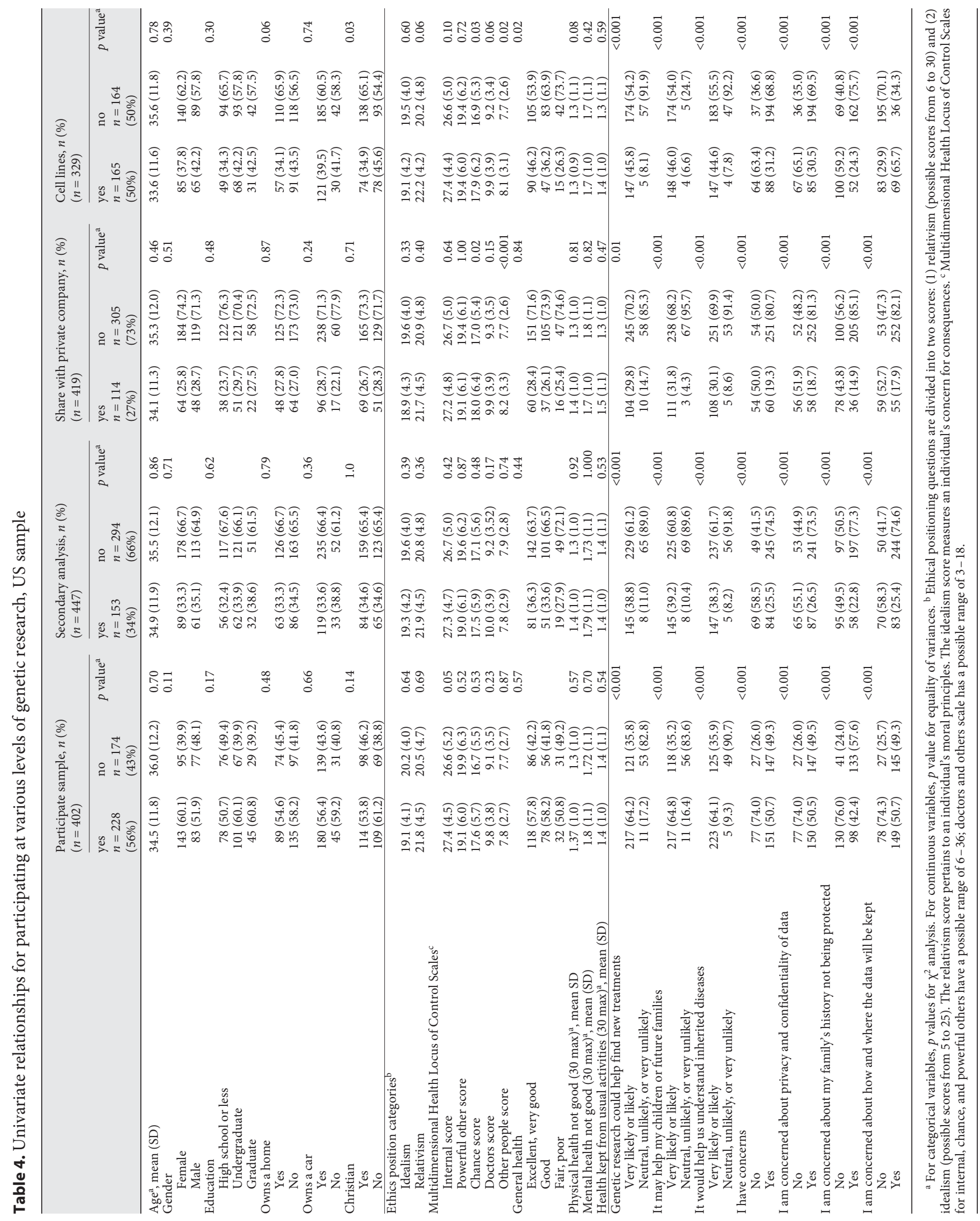


Table 5. Adjusted odds ratios for participating in various levels of genetic research, India sample

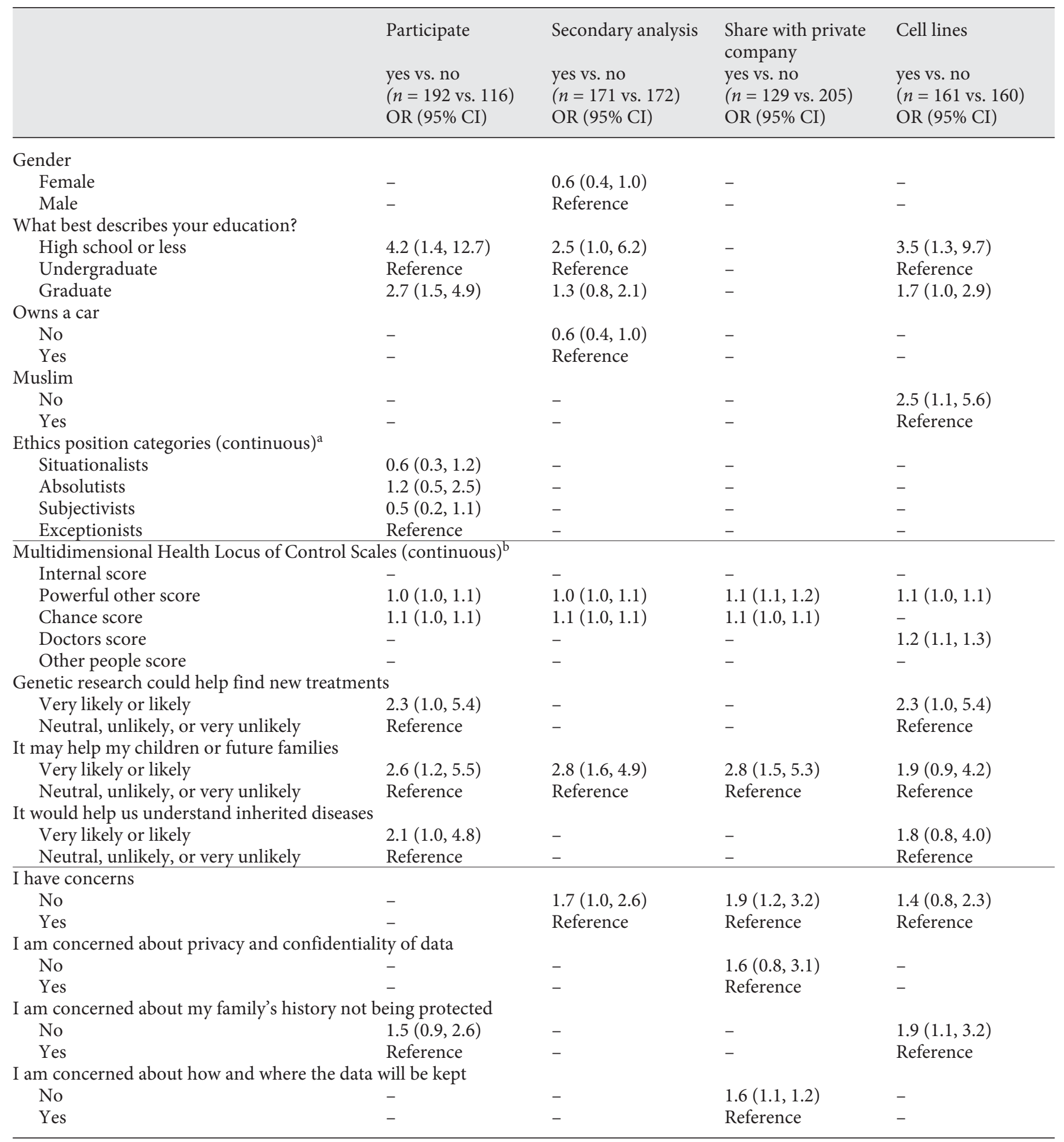

Variables not included in any of the final models are: age, own a house, and general health questions. ${ }^{\text {a }}$ Ethical positioning categories: situationalists favor securing the best possible consequence for all concerned; absolutists believe people should act in ways that are consistent with moral rules; subjectivists base their choices on personal considerations; and exceptionalists endorse moral rules as guides for action but admit that following rules will not always lead to the best outcome for all. ${ }^{\mathrm{b}}$ Multidimensional Health Locus of Control Scales for internal, chance, and powerful others have a possible range of 6-36; doctors and others scale has a possible range of 3-18. 
Table 6. Adjusted odds ratios for participating in various levels of genetic research, US sample

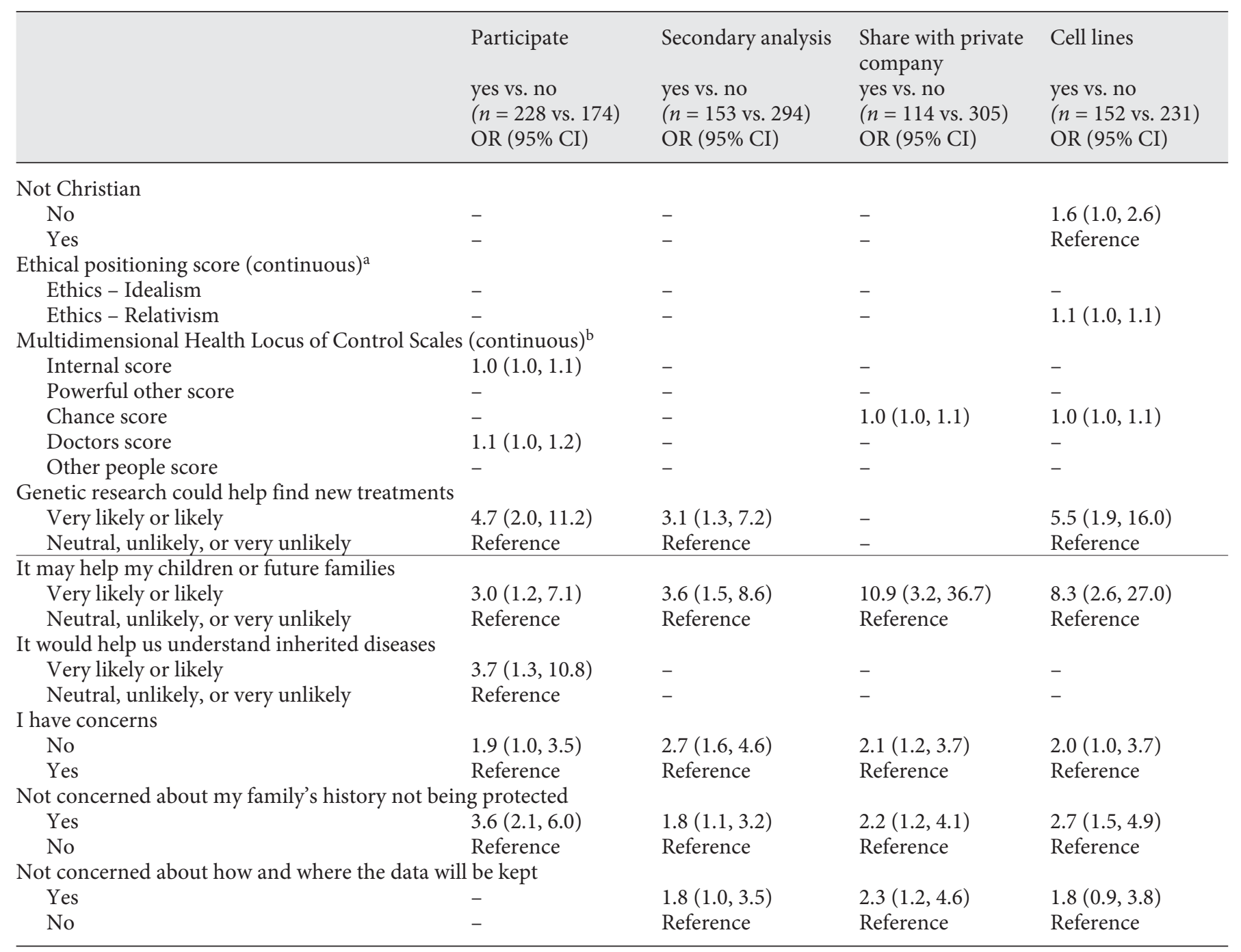

Variables not included in any of the final models are: age, gender, education, own a car, own a house, and general health questions. a Ethical positioning questions are divided into two scores: (1) relativism (possible scores from 6 to 30) and (2) idealism (possible scores from 5 to 25). The relativism score pertains to an individual's moral principles. The idealism score measures an individual's concern for consequences. ${ }^{\mathrm{b}}$ Multidimensional Health Locus of Control Scales for internal, chance, and powerful others have a possible range of 6-36; doctors and others scale has a possible range of 3-18.

CI 1.0-5.4 [India]; OR $=4.7,95 \%$ CI 2.0-11.2 [US]), and that children/future families would benefit $(\mathrm{OR}=2.6$, 95\% CI 1.2-5.5 [India]; OR = 3.0, 95\% CI 1.3-7.1 [US]). These commonalities were also reflected in increased odds of allowing their data to be used for secondary analysis, by private companies and for cell lines in both countries (Tables 5, 6). General health questions were not associated with any of the participation options that were asked about.

\section{Discussion}

There were common beliefs and concerns when accounting for health beliefs, ethical positions and health status across the two respondent populations. Participants from both countries expressed interest in participating in genetic research, particularly if they believed there were benefits to their children and/or future families. A belief that genetic research could have a positive 
impact on the future health of their families influenced participant willingness to be involved across all the genetic research participation options. That genetic research could help find new treatments resonated with both populations, but to a larger extent with US respondents.

Respondents' perceived general health did not influence willingness to participate in genetic research, nor did socioeconomic status. Ethical positions in general were not a factor, although some associations were noted for India respondents. Religious affiliation played a limited role: those who did not self-identify with a particular religion were more likely to agree to their DNA being used to create cell lines (US trend, India significant at $p<0.05$ ).

Respondents from either country who had concerns about genetic research were reluctant to participate, particularly with sharing of data with private companies. Outside of data sharing, the US respondents' concerns were primarily protection of family history and data management.

The findings above are consistent with other findings in US participants. In a study by Kerath et al. [2], US participants $(n=1,041)$ who did not support genetic research using their own genetic material indicated concern about the security of personal information. Of note in that study, younger subjects were less likely to respond yes to questions regarding societal benefit of genetic research. In our sample, with mean ages in the early 1930s, age was not significantly associated in the multivariate analysis. Several studies done in the US in the years surrounding the completion of the human genome project revealed common concerns around confidentiality, discrimination risk, misuse of information, and lack of benefit from genetic research [18-22]. In a more recent US study, concerns about privacy and confidentiality remained widespread $(n=4,659)$ [23]. General concerns about privacy were not necessarily related to willingness to participate in this large cohort study, but specific beliefs related to privacy were.

For our respondents ethical positioning was only associated with the use of DNA for cell lines in the US, and some trends for participation in India, depending on their idealism/relativism stances. Ethical components were examined in a study conducted for the Human Genetics Commission in the UK in 2001 [24]. Respondents $(n=1,249)$ overwhelmingly backed public ownership of new developments that make use of human genetic information. However, issues of consent and access were seen as vital and participants desired to retain the right to reconsent before new research was conducted on their
DNA samples. In a recent UK study, it was evident that research participants still preferred to retain some ownership of their DNA being used in research [25].

Demographic differences between the US and India included gender, socioeconomic and level of education; none of the demographics were significantly associated with participation for US respondents. However, Indian respondents with less education were more likely to participate in all genetic research participation options than those with higher education. Yet, lack of knowledge and widespread indifference to potential benefits of genomics in the population is considered a major challenge in India [9]. This differs from what has been noted in the US, where education was associated with an increased willingness to provide broad consent for use of genetic samples and data [26].

General health concerns of US and India respondents were not associated with participation. Our findings differ from those of a UK study that reported potential participants would participate to benefit society and their own families, but only if they themselves also benefited, or their health was not put at risk [27]. US participants in the personal genome project indicated they were participating to help society in general, but also had hopes of learning about disease at the personal and family levels [3].

Multidimensional health locus of control was a factor for respondents from India. In particular, powerful other and chance scores were significantly associated with willingness to participate in genetic research for all genetic research participation options. This finding reflects a belief that health is not dependent on behavior but external forces, and that these external forces influence decisionmaking about genetic research participation. Conversely, for the US respondents, powerful other (doctor) was only associated with the willingness to participate option in genetic research. Plus, there was a trend for internal score in US respondents, thus a belief that personal behavior affects health and this belief influenced willingness to participate.

Concern about DNA use by others was prevalent in respondents from both countries. A similar concern has been found in studies focused on biobanking. For example, in Australia, participant trust was less when biobanks shared information and materials with other researchers [28]. There was greater trust in public biobanks compared to private ones, and lesser trust in biobanks that shared data. A Swedish study reported that the possibility of DNA being used as a means of identification was a main concern for participation, along with concern that 
society would use the banked DNA for purposes other than the original proposed usage [29]. The main reported reasons for unwillingness to provide DNA samples were lack of personal relevance, discomfort with DNA usage, privacy issues, and discomfort with sharing something core to themselves, which is similar to the concerns our US and India respondents expressed. A UK study reported respondents had a strong sense of ownership of DNA and believed they owned their DNA and only allowed use for a particular study [25]. This preference for being involved in decisions about future use of DNA or use by others was reinforced by another UK study, although increased knowledge about genetics was associated with a less restrictive view [30]. Ultimately, confidentiality and data ownership are important issues for participants in genetic research and there is variation in attitudes toward data sharing $[3,4,26,28]$.

The acceptance of genetic research for helping children or future generations in respondents from both India and the US may be similar to what is seen with the Framingham Heart Study participants, which is a research project that has continued for generations and has a high rate of acceptance/willingness to participate in genetic research, even to the extent of creation of cell lines for research [31]. A high percentage of study subjects from the third generation (99\%) consented to DNA extraction and cell line creation. The only area where subjects were less interested in sharing data was with private companies.

\section{Limitations}

The digital workforce accessed for this study reflects a population with access to and facility with the internet, which may differ from the general population. Participants in this study reflect only 2 countries, limiting generalizability to people from other countries. Respondents were individuals who used mTurk and responses may not be representative of the general population of their country of residence. Furthermore, these early adopters of innovation (i.e., mTurk) may also be more prone to acceptance of the "innovation" of genetic research. However, mTurk workers are generally a heterogeneous population [12]. Responses could potentially be subject to social desirability, thus biased. The survey did not include questions related to the consent process for additional usage of biosamples beyond participation. Reconsent for additional use of biological samples was raised as a concern in other studies [24, 25]. Participants answered questions about what they might do in the future in terms of genetic research, which may not be what they would actually do in real life.

\section{Conclusions}

Understanding who is willing to participate in genetic research has important implications for the generalizability of genetic research findings. When accounting for demographic factors and traits (such as ethical positions, multidimensional health locus of control, health status) in the US and India respondents there were similarities in beliefs and concerns regarding participation in genetic research and use of genetic material. Concurrence of beliefs suggests these particular concerns may be common across countries. Consideration of commonalities may be important to increase participation in genetic research in different countries. Furthermore, these findings could be used to develop educational materials that address these concerns.

\section{Acknowledgments}

Drs. Dye, Li, Demment, Dozier, and Mr. Chang received funding from Award Number Grant UL1 TR000042 from the National Center for Advancing Translational Sciences, National Institutes of Health.

The content is solely the responsibility of the authors and does not necessarily represent the official views of the National Center for Advancing Translational Sciences or the National Institutes of Health.

\section{Statement of Ethics}

This research was reviewed and approved by the University of Rochester's Research Subjects Review Board.

\section{Disclosure Statement}

There are no conflicts of interest for disclosure. 


\section{References}

1 World Health Organization: Genomics and World Health: Report of the Advisory Committee on Health Research. Geneva, World Health Organization, 2002. http://apps.who. int/iris/bitstream/10665/42453/1/a74580.pdf (accessed January 12, 2016).

$>2$ Kerath S, Klein G, Kern M, Shapira I, Witthuhn J, Norohna N, Kline M, Baksh F, Gregersen P, Taioli E: Beliefs and attitudes towards participating in genetic research - a population based cross-sectional study. BMC Public Health 2013;13:1-9.

3 Zarate O, Brody J, Brown P, Ramirez-Andreotta M, Perovich L, Matz J: Balancing benefits and risks of immortal data: participants' views of open consent in the personal genome project. Hastings Cent Rep 2016;46:36-45.

-4 Alahmad G, Hifnawy T, Abbasi B, Dierickx K: Attitudes toward medical and genetic confidentiality in the Saudi research biobank: an exploratory survey. Int J Med Inform 2016;87: 84-90.

$\checkmark 5$ Dye T, Li D, Demment M, Groth S, Fernandez ID, Dozier A, Chang J: Sociocultural variation in attitudes toward use of genetic information and participation in genetic research by race in the United States: implications for precision medicine. J Am Med Inform Assoc 2016; 23:782-786.

6 H3Africa human heredity \& health in Africa. http://www.h3africa.org/about (accessed December 10, 2015).

7 Dove E, Knoppers B, Zawati M: An ethics safe harbor for international genomics research? Genome Med 2013;5:1-11.

$>8$ Chen H, Pang T: A call for global governance of biobanks. Bull World Health Organ 2015; 93:113-117.

9 Chakrabarty S, Kabekkodu S, Brand A, Satyamoorthy K: Perspectives on translational genomics and public health in India. Public Health Genomics 2016;19:61-68.

10 Crump M, McDonnell J, Gureckis T: Evaluating Amazon's mechanical turk as a tool for experimental behavioral research. PLoS One 2013;8:e57410.

11 Rand D: The promise of Mechanical Turk: how online labor markets can help theorists run behavioral experiments. J Theor Biol 2012;299:172-179.

12 Paolacci G, Chandler J: Inside the Turk: understanding Mechanical Turk as a participant pool. Curr Dir Psychol Sci 2014;23:184-188.

13 Hamburg M: Basic Statistics: A Modern Approach, ed 3. San Diego, Harcourt Brace Jovanovich, 1985.
14 Green D, Cushman M, Dermond N, Johnson EA, Castro C, Arnett D, Hill J, Manolio TA: Obtaining informed consent for genetic studies: the multiethnic study of atherosclerosis. Am J Epidemiol 2006;164:845-851.

15 Wallston K, Wallston B, DeVellis R: Development of the Multidimensional Health Locus of Control (MHLC) Scales. Health Educ Monogr 1978;6:160-170.

$>16$ Forsyth D: A taxonomy of ethical ideologies. J Pers Soc Psychol 1980;39:175-148.

17 Forsyth D, Nye J, Kelly K: Idealism, relativism, and the ethic of caring. J Psychol 1988; 122:243-248.

18 Bates BR: Public culture and public understanding of genetics: a focus group study. Public Underst Sci 2005;14:47-65.

19 Espeland MA, Dotson K, Jaramillo SA, Kahn SE, Harrison B, Montez M, Foreyt JP, Montgomery B, Knowler WC, Look ARG: Consent for genetics studies among clinical trial participants: findings from Action for Health in Diabetes (Look AHEAD). Clin Trials 2006;3: 443-456.

20 Godard B, Marshall J, Laberge C: Community engagement in genetic research: results of the first public consultation for the Quebec CARTaGENE project. Community Genet 2007;10:147-158.

21 Henderson G, Garrett J, Bussey-Jones J, Moloney ME, Blumenthal C, Corbie-Smith G: Great expectations: views of genetic research participants regarding current and future genetic studies. Genet Med 2008;10:193-200.

-22 McQuillan GM, Pan Q, Porter KS: Consent for genetic research in a general population: an update on the National Health and Nutrition Examination Survey experience. Genet Med 2006;8:354-360.

23 Platt J, Bollinger J, Dvoskin R, Kardia S, Kaufman D: Public preferences regarding informed consent models for participation in population-based genomic research. Genet Med 2014;16:11-18.

24 Human Genetics Commission: Public attitudes to human genetic information: people's panel quantitative study conducted for the human genetics commission. https://www. ucdmc.ucdavis.edu/biorepositories/pdfs/genomics-biobank/Public-attitudes-to-humangenetic-information.pdf (accessed September 2016).
25 Kelly S, Spector T, Cherkas L, Prainsack B, Harris J: Evaluating the consent preferences of UK research volunteers for genetic and clinical studies. PLoS One 2015;10:1-12.

-26 Ewing A, Erby L, Bollinger J, Tetteyfio E, Ricks-Santi L, Kaufman D: Demographic differences in willingness to provide broad and narrow consent for biobank research. Biopreserv Biobank 2015;13:98-106.

-27 Hallowell N, Cooke S, Crawford G, Lucassen A, Parker M, Snowdon C: An investigation of patients' motivations for their participation in genetics-related research. J Med Ethics 2010; 36:37-45.

28 Critchley C, Nicol D, Otlowski M: The impact of commercialization and genetic data sharing arrangements on public trust and the intention to participate in biobank research. Public Health Genomics 2015;18:160-172.

29 Melas P, Sjöholm L, Forsner T, Edhborg M, Juth N, Forsell Y, Lavebratt C: Examining the public refusal to consent to DNA biobanking: empirical data from a Swedish populationbased study. J Med Ethics 2010;36:93-98.

30 Lewis C, Clotworthy M, Hilton S, Magee C, Robertson M, Stubbins L, Corfield J: Consent for the use of human biological samples for biomedical research: a mixed methods study exploring the UK public's preferences. BMJ Open 2013;3:pii:e003022.

31 Levy D, Splansky GL, Strand NK, Atwood LD, Benjamin EJ, Blease S, Cupples LA, D’Agostino RB, Sr., Fox CS, Kelly-Hayes M, Koski G, Larson MG, Mutalik KM, Oberacker E, O’Donnell CJ, Sutherland P, Valentino M, Vasan RS, Wolf PA, Murabito JM: Consent for genetic research in the Framingham heart study. Am J Med Genet A 2010;152A:12501256.

32 Hennessy C, Moriarty D, Zack M, Scherr P, Brackbill R: Measuring health-related quality of life for public health surveillance. Public Health Report 1994;109:665-672.

-33 Wenzel L, Bowen D, Habbal R, Leighton N, $\mathrm{Vu} \mathrm{T}$, Anton-Culver $\mathrm{H}$ : Testing targeted approaches to enhance Cancer Genetics Network minority recruitment within Asian populations. Community Genet 2008;11:223240 .

34 Olsen S, Malvern K, May B, Jenkins I, Griffin C: Partnership with an African American sorority to enhance participation in cancer genetics research. Community Genet 2008;11: 201-207. 